\title{
Women and Tobacco- An Overview
}

\author{
Namratha Kulkarni* \\ Department of Community Medicine, India
}

Submission: February 01, 2017; Published: March 27, 2017

"Corresponding author: Namratha Kulkarni, Department of Community Medicine, JJMMC, India, Tel: 8971780515, Email: namratha.d.kulk@gmail.com

\begin{abstract}
Tobacco consumption is the single most important avoidable risk factor in the growth of non communicable diseases all over the world [1]. Tobacco use is world's number one killer and it kills up to half of its regular users. About $22 \%$ of women in developed countries and nine percent of women in developing countries smoke tobacco. In addition, many women in south Asia chew tobacco. Tobacco causes negative effects on a person's health as soon as he/she starts using it in any form either regularly or occasionally. Tobacco kills both men and women but sex-specific differences exist.

There are many gaps in the data about the health impact of tobacco use on girls and women of all ages and throughout the life-course. The use of multiple forms of tobacco in India complicates the efforts to reduce its overall impact on public health. In order to reverse the rising tobacco epidemic by effective health policies, community based epidemiological studies on tobacco use are required to quantify the problem and to identify the determinants and their distribution.
\end{abstract}

\section{Introduction and Statistics}

Tobacco consumption is the single most important avoidable risk factor in the growth of non communicable diseases all over the world [1]. Tobacco use is world's number one killer and it kills up to half of its regular users. Tobacco Causes $10 \%$ of deaths worldwide, nearly 5.4 million a year of which $80 \%$ occur in developing countries [2]. About 250 million women in the world are daily smokers. About $22 \%$ of women in developed countries and nine percent of women in developing countries smoke tobacco. In addition, many women in south Asia chew tobacco [3].

Within 150 years of Columbus's finding "strange leaves" in the New World, tobacco was being used around the globe. Its rapid spread and widespread acceptance characterize the addiction to the plant Nicotina tobacum. Only the mode of delivery has changed. In the $18^{\text {th }}$ century, snuff held sway; the $19^{\text {th }}$ century was the age of the cigar; the $20^{\text {th }}$ century saw the rise of the manufactured cigarette and with it a greatly increased number of smokers [3].

Roughly $10 \%$ of the world's tobacco smokers live in India representing the second largest group of smokers in the world after China. India is also the third largest producer of tobacco leaves in the world. Tobacco use patterns in India are unique and reflect longstanding cultural practices. Two features stand out; bidis are more common than cigarettes; and chewing tobacco is widely prevalent [1].
In India, each year nine lakh people die due to tobacco related diseases and more than 2200 Indians die every day due to tobacco use. Tobacco use is responsible for $40 \%$ of all cancers in India. India is having highest number of oral cancer cases in the world among which $90 \%$ are tobacco related [2]. According to NFHS-3 estimates, 120 million Indians smoke of whom $11 \%$ of women aged 15 to 49 years consume some form of tobacco either smoked or non-smoked. The prevalence of tobacco use in any form among rural women in the age group of 15 to 49 years is $12.9 \%$ as compared to $6.7 \%$ in the urban women. Estimates show that, $8.5 \%$ of pregnant mothers and $10.8 \%$ of breastfeeding mothers use tobacco in some form [4].

Tobacco causes negative effects on a person's health as soon as he/she starts using it in any form either regularly or occasionally. Short term effects include tooth decay, breathing problems exaggeration of asthma. Long term effects include cardio-vascular diseases, reproductive disorders, birth defects, brain shrinkage/cognitive dysfunction, Alzheimer's disease, stroke, cataract/blindness, cancers and respiratory disorders $[2,3]$.

Tobacco kills both men and women but sex-specific differences exist. A high prevalence of smokeless tobacco use is an additional risk for premature death, especially among women. Tobacco use is one of the top six leading attributable risk factors for chronic diseases in women aged 20 years and above [3]. 
Second Hand Smoking (SHS) exposure leads to added morbidity in pregnant women and their newborns. Studies have also shown association of SHS with low birth weight and genetic mutations in the newborn. Poor pregnancy outcomes from tobacco use during pregnancy include still births, increase in placental weight, male fetus wastage, low birth weight, lower gestational periods (preterm) [3,5] delayed conception, sudden infant death syndrome, premature rupture of membranes, abruptio placenta and placenta pre via $[3,6]$. India, has now become the signatory nation to "Framework Convention on Tobacco Control" (FCTCWHO, 2003) [7], a first ever international public health treaty on any one health issue, and is coming out with stringent tobacco control policies.

The use of multiple forms of tobacco in India complicates the efforts to reduce its overall impact on public health. In order to reverse the rising tobacco epidemic by effective health policies, community based epidemiological studies on tobacco use are required to quantify the problem and to identify the determinants and their distribution. This information has to be area specific because of a strong correlation with socio-cultural characteristics and existence of wide variations in tobacco use prevalence as in nationwide surveys [8]. There are many gaps in the data about the health impact of tobacco use on girls and women of all ages and throughout the life-course [9].

\section{Historical Overview of Tobacco}

"Tobacco" appears as old as human civilization. There are various theories which explore the origin of the word Tobacco. The word "tobacco" is thought to be derived from the Arabic word "Tabaq" which means 'Euphoria producing herb'. It is also said that the word tobacco comes from the island of Tobago in the Caribbean. Sources also refer the origin of this word to Tabasco State in Mexico. Another theory states that the word Tobacco is derived from the Spanish word 'Tobaca' which is a Y-shaped instrument used by the early American Indians to inhale snuff [6].

The cultivation of tobacco plant dates back probably to 8000 years, when Nicotina rustica and Nicotina tabaccum, the two species of the plant were dispersed by American Indians throughout the southern and northern American continent. Tobacco was known to be an important article of the inhabitants of South America since tobacco seeds were discovered in the archeological excavations of Mexico and Peru, and in the remains of permanent settlements built around 3500 BC [10]. Tobacco belongs to the plants family of nightshade or family Solanaceae which contains the Genus Nicotina. All modern commercial varieties of tobacco descend directly from N.tobacco [11].

Portuguese traders introduced tobacco in India during 1600. Tobacco was first introduced in the kingdom of Adil Shahi, the capital city of Bijapur, presently in Karnataka, in South India along the trading routes of Portuguese which were mainly the Cochin and Goa, on the West coast of India and Machalipatnam along the East coast. Keeping the health hazards of tobacco in mind, the King Akbar advised tobacco smoke to be first passed through water for purification. This created Hookah (Hubble-bubble). The use of tobacco is mentioned even in the Subhashitratnabhandara, the seven Sanskrit verses of unknown date and authorship $[6,10,12,13]$.

Tobacco was easily assimilated into the cultural rituals of many societies and this was attributed mainly to its medicinal and also intoxicating properties. Tobacco soon became a valuable commodity in barter trade and its use spread rapidly [6]. By $20^{\text {th }}$ century, tobacco use had spread all over the world in numerous forms and at the same time, research have attributed to various new diseases due to tobacco.

\section{Tobacco and Economics}

India is the world's third largest tobacco producing country after China and Brazil and produced more than $10 \%$ of the world's raw tobacco during 2003-2004, but ranked only ninth globally as an exporter of tobacco and tobacco products [1]. Andhra Pradesh, Gujarat, Karnataka and Uttar Pradesh together produce over $90 \%$ of the total tobacco in the country. In India, the annual tobacco consumption has increased from 360 million kgs in 1981 to 470 million kgs in 2001, with the production of tobacco increasing from 480 million kgs in 1981 to 601 million kgs in 2001 [6].

In India, tobacco is the fourth largest contributor with an average of $10 \%$ to the union excise revenue collection, after textiles, petroleum products and iron and steel industries. But its contributions are easily outweighed by the conservatively estimated costs incurred due to tobacco related diseases. Its total contribution in terms of excise revenue and foreign exchange was 8681crores (2004-2005) whereas an Indian Council of Medical Research (ICMR) study reported that the total cost to the country was estimated to be 27,761 crores which is three folds the contributions from tobacco industry mainly due to tobacco related cancers, coronary artery disease and chronic obstructive lung diseases $[6,14,15]$.

Tobacco is a labor-intensive crop in India. Growing, harvesting and processing tobacco represent the means of livelihood of a large number of agricultural laborers. National employment surveys by the National Sample Survey Organization (NSSO) place the direct and indirect tobacco workforce in India at approximately 7 million during 200405 , representing approximately $1.5 \%$ of overall employment in the formal sector. This includes workers engaged in tobacco farming, manufacturing and the wholesale/retail trade, either full or part time. The vast majority of these jobs, perhaps more than 4 million, are in bidi manufacturing, with women making up half of the tobacco-related workforce. Tobacco farming and processing of tobacco products is considered as economically profitable and a major source of employment and revenue by governments. There are popular misconceptions that tobacco 
control measures such as an increase in tax and price will lead to smuggling and banning tobacco in restaurants and bars will hurt business $[1,16,17]$.

\section{Tobacco and its Contents}

With only little known about the individual effects of hundreds of chemical substances present in tobacco, its use reflects a complex interplay of pharmacological, psychological and socioeconomic factors. With more than 599 additives (approved as food additives) used in manufacturing cigarettes, over 4000 chemical compounds are produced by burning a cigarette, many of which are toxic and/or carcinogenic. Forty three known carcinogens are in the main stream smoke or side stream smoke or both $[18,19]$.

Smokeless tobacco, also known as chewing tobacco or spit tobacco contain a minimum of 28 cancer causing chemicals with formaldehyde (an embalming fluid), nitrosamine being the major carcinogens and Uranium 235 and polonium 210, the nuclear products [20].

With Nicotine an alkaloid, being the most active tobacco ingredient that acts on brain and produces the addiction effect, it produces various physiological effects such as arousal or relaxation, enhanced concentration, vigilance, appetite suppression. Hematological effects mainly include increase in the adhesiveness of platelets. Increased growth hormone and inhibition of prostacyclin synthesis are the endocrine effects. Lipolysis and increased energy expenditure are the metabolic effects. Effects of nicotine on cardiovascular system include increased heart rate and cardiac contractility, increase in the blood pressure, cutaneous vasoconstriction, systemic venoconstriction and catecholamine release [21,22].

\section{Women and Tobacco}

"Gender and tobacco with an emphasis on marketing to women" was the theme for 2010's World No Tobacco Day, which is celebrated every year on $31^{\text {st }}$ May. Tobacco use is also one of the top six leading attributable risk factors for chronic diseases leading to death in women aged 20 years and above. Of more than 5 million people who die every year from tobacco related cause, approximately 1.5 million are women. Most (75\%) of these women live in low- and middle-income countries. Unless urgent measures are taken, tobacco could kill up to 8 million people every year by 2030 , of which 2.5 million would be women [23]. There is an alarming trend that links poverty with tobacco use. Poor families are more likely to include smokers than richer families. Poor families spend a substantial part of their total expenditures on tobacco-often more than they spend on education or health care [9].

Women are one of the biggest targets of the tobacco industry. The tobacco industry has long fostered the false idea that tobacco is linked to women's empowerment by suggesting that cigarette smoking symbolizes high fashion, freedom, and "modern" styles and values, and that it even promises weight reduction. The industry actively targets women because comparatively few women currently use tobacco, and women are increasingly able to afford tobacco.

Large companies sponsor events such as women's tennis tournaments and disco dances to create a public image of smoking as a promoter of health and relaxation. "Female brands", "light" cigarettes, low prices, easy availability, and free samples help these marketing strategies succeed among young women. In India, where it may not be culturally "correct" for women to buy cigarettes openly, companies have offered to deliver them to the home.

Modern marketing seeks to attach symbolic meaning to brands, associating products with psychological and social needs in a coordinated strategy that surrounds the consumer with stimuli. Advertising is used to reduce fears about tobacco use and to associate products with dazzling blue skies and mountains, happiness, and healthy sports activities [9].

According to the National Family Health Survey 2005-2006, tobacco use is more prevalent in rural areas than in urban areas both among men and women. Among women, 0.5\% in urban areas and $2 \%$ in rural areas used smoking form of tobacco products and about $6 \%$ of urban women and about $12 \%$ of rural women used smokeless tobacco. About 8\% percent of Indian women aged 15-49 years chewed tobacco in the form of paan masala and gutka [8]. $5 \%$ of antenatal mothers and $10.8 \%$ of breastfeeding women use tobacco in some form [4].

A cross sectional study done during 1985-1986 surveyed 13,588 men and women aged 25-64 years in Delhi, India, reported that women with no education were 3.7 times (95\% $\mathrm{CI}=2.86-4.82$ ) more likely to be smokers. As compared to Hindu women, Muslim women were more likely to be smokers $(\mathrm{OR}=3.47,95 \% \mathrm{CI}=2.81-4.28)$ [24].

A study carried out in coastal South India in 1994 reported that $2 \%$ of females were regular pan tobacco chewers whereas $11 \%$ females chewed occasionally. Furthermore, $14 \%$ of females under the age of ten years had at least one habit. (Chewing pan-tobacco, smoking bidi or cigarettes, or drinking alcoholic beverages) [25].

A 1997 survey in Mumbai amongst the adults aged 35 years and above showed a high prevalence $(57.5 \%)$ of tobacco use among women, consuming exclusively smokeless tobacco products. The most common form being mishri [26].

In 1997, another house to house survey was done to study the chewing habits among 110 women aged 15 years and above in the rural Pondicherry. Though the study reported that the prevalence of betel quid with tobacco was as high as $13.7 \%$, the mean age of starting betel quid with tobacco was 16.5 years [8].

A cross sectional study was conducted in a rural area of Akhta village of Sitamarhi district in Bihar to study the tobacco use during June-July 2000 showed $0.3 \%$ smoking and $6.2 \%$ 
smokeless tobacco use among children (<15years). Smokeless tobacco use among adults was $32.7 \%$ with $21.7 \%$ in females. Tobacco tooth powder (41.3\%) among females was most commonly used smokeless tobacco products. Prevalence of smoking was $23.4 \%$ in females, the most prevalent form $(>80 \%)$ was beedi smoking both in men and women. The study does not tell us about the quitting patterns nor social factors such as initiation age of tobacco etc [27].

A study on tobacco use among school personnel in Bihar in 2001 reported that prevalence of tobacco use among women was as high as $77.0 \%$. The smokeless tobacco use among women was $53.4 \%$. Although smoking among women in India is generally socially not acceptable, prevalence of smoking among women in this sample was quite high (31\%) and most of it was cigarette smoking (26.9\%) [28].

The Study on prevalence of Tobacco use in Karnataka in 2001 reported current tobacco use of $15.2 \%$ among females and the prevalence increased with age reaching the peak level above the age of 70 years. Prevalence of tobacco use was higher in rural areas as compared to urban areas in most age groups, except among teenagers where prevalence was comparable or higher than rural areas. This study also reported that prevalence of current smoking was less than the prevalence of current smokeless tobacco use. Most of the current tobacco users were smokeless tobacco users. According to this study, only $0.6 \%$ of females in Karnataka smoked. The prevalence of smokeless tobacco users among females was higher than males. Prevalence of smokeless tobacco use increased with age for both sexes. It was lower among educated women although clear-cut reducing trends with increasing education were not observed in all agegroups among men. Prevalence of smokeless tobacco use was comparatively lower among women with family income above Rs 5000 per month. According to this study, Betel-tobacco quid was found to be fairly popular in Karnataka with prevalence being $14.2 \%$ (26.9\% among males and $0.6 \%$ among females) in Karnataka.

An inverse association of decrease in prevalence rates of betel-tobacco quid use with increasing educational levels was observed in different age-groups in Karnataka. An inverse association of betel-tobacco quid use with increasing family income levels was observed in this study [29].

Three annual urban and rural cross-sectional surveys were carried out between 2001 and 2003 involving a total of 35,446 adults, of whom $54.3 \%$ were females and $51.0 \%$ were rural dwellers. The survey was carried out to determine the extent of all forms of tobacco usage in adult Bangladesh is in relation to gender and locality. The results revealed that current smoking and gul usage in females were $2.3 \%$ and $1.5 \%$ respectively. Chewing tobacco was more common in females $(21.6 \%)$ than males (19.4\%). Females were less likely to smoke or use gul or use dual tobacco but more likely to chew tobacco [30].
A study was done in 2003-2004 on 7891 in Ballabgarh block of Faridabad dist to determine the rural, urban and urban-slum differences in patterns of tobacco use. The study revealed that the prevalence of tobacco was higher in rural areas $(7.7 \%)$. Although the overall prevalence was low in urban areas, it was much higher in the urban slums (11.9\%) [31].

In the study done in 12 districts of Karnataka during GATS survey in 2003-2004, point prevalence of tobacco use amongst $13-15$ year old was $4.9 \%$. Current tobacco use was $2.1 \%$ in females. At home, more females were using smokeless form of tobacco as compared to smoking form (28.2\% Vs 13.1\%) [32].

A cross-sectional survey using personal interviews was carried out on 832 individuals $>15$ years of age in 2004 at Manipal, Karnataka. The prevalence of tobacco use was $15.7 \%$ among women. Among current daily users of tobacco, 55.7\% of women used tobacco only in the chewing form. Use of snuff alone was reported by $4.3 \%$ (95\% CI: 2.9-5.7) of the population, and most snuff users were women. None of the women in this study reported smoking [33].

In a study on prevalence of risk factors for non communicable diseases in a rural area of Faridabad district of Haryana done in 2004, the age adjusted prevalence of daily smoked tobacco was $13 \%$ for women where as smokeless tobacco use was $1.2 \%$ women [34].

A study was conducted in Noida city during July- December 2005 among adolescents. It reported that 5.3 per cent had ever smoked cigarette exclusively with $5.0 \%$ in girls. Amongst the girls ever used zarda was reported as $0.4 \%$ and $0.4 \%$ smoked beedis. Nearly 80 per cent of girls $\leq 15 y$ rs initiated the habit of tobacco before the age of 11yrs [35].

A study done to assess pattern and risk factors associated with tobacco consumption in various forms among adult women above 18 years of age in a low socioeconomic community of Manora Island, Karachi reported 52\% tobacco consumption. Use of huqqa (hubble bubble) was more prevalent (79\%). Tobacco consumption (OR=3.16, 95\% CI=1.13-7.72). Tobacco consumption was more in illiterates, in married women, in women aged above 30 years and those living in joint families. Women having household income more than Rs 5000 were in the habit of consuming tobacco $(\mathrm{OR}=2.63,95 \% \mathrm{CI}=1.36-5.09)$ resulting in more financial difficulties $(\mathrm{OR}=4.72,95 \% \mathrm{CI}=2.45$ 9.81). Women consuming tobacco reported anxiety related symptoms more as compared to women who did not consume tobacco [36].

The conducted in 2005, reported that out of 1255 adolescents, $35.6 \%$ were girls, ever use of tobacco was reported to be $30.2 \%$ in females where as current use of tobacco in girls was $31.6 \%$. The smokeless use of tobacco was common among girls when compared to boys. $26.4 \%$ of girls reported that the first the thing in the morning they needed is tobacco [37]. 
A cross-sectional study was conducted in the rural area of Saoner, Nagpur district of Maharashtra from May 2008 to November 2008 to estimate the prevalence of common risk factors for non communicable diseases among people above 15 years in rural population. The study reported that among women none were smoking tobacco; while the prevalence of smokeless tobacco use was $32.8 \%$ (95\% CI $30.6 \%$ - 35.0\%). It was more in the older age group of 55-64 years. Snuff and tobacco toothpaste were the most common forms used [38].

In a study done in Bangalore during 2009-2010, it was reported that majority of respondents (84.6\%) reported negative perceptions about smokers while $20.4 \%$ of respondents reported positive perceptions. Female students reported significantly higher disapproval rate (negative perceptions) for smoking compared to male students $(89.7 \%$ Vs $71.6 \%$ in case of male smoker; $81.2 \%$ Vs $67.3 \%$ in case of female smokers) [39].

To study the prevalence of non-communicable disease risk factors in Cambodia, a nationwide cross sectional survey was carried out from February to April 2010 in which 4.8\% smoking was reported among women. The proportion of current users of smokeless tobacco was 6.8 times higher in women than men. Betel quid was on average used more frequently by women than by men (3.5 vs. 2.3 times per day) [40].

A study done to assess the prevalence of tobacco use and the extent of awareness about the prominent legislative measures against tobacco in 15 randomly selected high schools in an educational sub district of Kerala reported that out of total 1473 students who participated in the study, $21 \%$ of them were females. The overall prevalence of current tobacco users was $8 \%$. Females were more aware of the smoking ban than males it also reported that $41.5 \%$ of the students knew about the link between oral cancer and tobacco with the awareness being greater among females than males (64.3\% vs. $35.4 \%)$ [41].

Global Adult Tobacco survey was done during 2009-2010 in India. This survey reported that the current tobacco use in any form is $47.9 \%$ in males and $20.3 \%$ in females out of which current female smokers are $2.9 \%$ of which $1.9 \%$ of them smoke bidi $18.4 \%$ of the women use smokeless tobacco and $25.8 \%$ of the females started using tobacco before the age of 15 years [42].

It has become the need of the hour to provide enough evidence on the correlates of tobacco use in the community to assist government policy makers, health professionals and the public in developing realistic models towards effective tobacco control to cater to different sections of community in need.

\section{References}

1. John RM, Rao RK, Rao MG, Moore J, Deshpande RS, et al. (2010) The Economics of Tobacco and Tobacco Taxation in India. International Union against Tuberculosis and Lung Diseases, France.

2. World Health Organization (2010) Helping people Quit Tobacco: A manual for Doctors and Dentists.
3. Mackay J, Eriksen M (2002) The Tobacco Atlas. World Health Organization, Switzerland.

4. International Institute for Population Sciences (IIPS), Macro International (2007) National Family Health Survey (NFHS-3), India.

5. Sinha DN (2004) Report on Oral Tobacco Use and its Implications in South East Asia. WHO, India.

6. Reddy Shrinath K, Gupta PC (2004) Report on Tobacco Control in India-Executive Summary. Ministry of Health and Family Welfare, Government of India.

7. http://www.who.int/fctc/en/

8. Jagadeeshan M, Rotti SB, Danabalan M, Narayan K (2007) Chewing habits among Rural Women in Pondicherry. Indian J of Comm Med 22(2): 74-81.

9. http://www.who.int/tobacco/publications/

10. Gupta PC, Hamner JE, Murti PR (1993) Control of Tobacco related Cancers and other diseases. Oxford University Press, India.

11. Arora M (2003) The Tobacco Journey: Seeds of a Menace. Health for Millions 29(30): 4-6.

12. Chattopadhayay A (2002) Emperor Akbar as a healer and his eminent physicians. Bull Indian Inst Hist Med Hyderabad 30(2): 151-157.

13. Gode PK (1969) Studies in Indian cultural history, Vishveshvarananda Vedic Research Institute, Punjab, India.

14. Gupta PC (2006) Tobacco control in India. Indian J Med Res 123, pp. 579-582.

15. http://www.who.int/

16. http://www.who.int/

17. Barry M (1991) The influence of the US tobacco industry on the health economy and environment of developing countries. N Engl J Med 324(13): 917-920.

18. http://quitsmoking.about.com/cs/nicotineinhaler/a/cigingredients/

19. http://www.sfc.org.nz/infohealtheffects.php

20. http://www.intheknowzone.com/tobacco/what/

21. Govt of India (2005) Effects of nicotine Manual for Tobacco cessation. Ministry of Health and Family Welfare, New Delhi, India.

22. Jain R, Mukherjee R (2003) Biological basis of nicotine addiction. Indian J of Pharmacology 35(5): 281-289.

23. http://www.who.int/gender/

24. Narayan KM, Chadha SL, Hanson RL, Tandon R, Shekhawat S, et al (1996) Prevalence and patterns of smoking in Delhi: A cross sectional study. BMJ 312(7046): 1576-1579.

25. George A, Varghese C, Sankaranarayan R, Nair MK (1994) Use of tobacco and alcoholic beverages by children and teenagers in a low income coastal community in south India. J Cancer Educ 9(2): 111-113.

26. PC Gupta (1996) Survey of socio- demographic characteristics of tobacco use among 99,598 individuals in Bombay, India using handheld computers. Tobacco Control 5(2): 114-120.

27. Sinha DN, Gupta PC, Pednekar MS (2003) Tobacco Use in a Rural Area of Bihar. Indian J community Med 28(4): 167-170.

28. Sinha DN, Gupta PC, Pednekar MS, Jones JT, Warren CW (2002) Tobacco use among school personnel in Bihar, India. Tob Control 11(1): 82-83.

29. Chaudhary K (2001) Prevalence of Tobacco Use in Karnataka and Uttar Pradesh in India. Indian Council of Medical Research, WHO, Switzerland. 
30. Flora MS, Mascie-Taylor CGN, Rahman M (2009) Gender and locality differences in tobacco prevalence among adult Bangladeshis. Tobacco Control 18(6): 445-450.

31. Gupta V, Yadav K, Anand K (2010) Patterns of tobacco use across rural, urban, and urban-slum populations in a North Indian community. Indian J Community Med 35(2): 245-51.

32. Gururaj C, Girish N (2007) Tobacco Use amongst Children in Karnataka. Indian J Pediatr 74(12): 1095-1098.

33. Daniel AB, Nagraj K, Kamath R (2008) Prevalence and determinants of tobacco use in a highly literate rural community in southern India. Natl Med J of India 21(4): 163-165.

34. Krishnan A, Shah B, Lal V, Shukla DK, Paul E, et al. (2008) Prevalence of risk factors for non-communicable disease in a rural area of Faridabad district of Haryana. Indian J Public Health 52(3): 117-124.

35. Narain R, Sardana S, Gupta S, Sehgal A. Age at initiation \& prevalence of tobacco use among school children in Noida, India: A cross-sectional questionnaire based survey. Indian J Med Res 133: 300-307.

36. Nisar N, Billoo N, Gadit AA (2005) Pattern of tobacco consumption: among adult women of low socioeconomic community Karachi Pakistan. J Pak Med Assoc 55: 111-114.
37. Madan Kumar PD, Poorni S, Ramachandran S (2006) Tobacco use among school children in Chennai city, India. Indian J of Cancer 43(3): 127-131.

38. Bhardwaj SD, Shewte MK, Bhatkule PR, Khadse JR (2012) Prevalence of risk factors for non-communicable disease in a rural area of Nagpur district, maharashtra-A WHO STEP wise approach. Int J Biol Med Res 3(1): 1413-1418.

39. Bhojani UM, Elias MA, Devadasan N (2011) Adolescents' perceptions about smokers in Karnataka, India. BMC Public Health 11: 563.

40. Oum S, Prak PR, Khuon EM, Mey V, Aim S, et al. (2010) Prevalence of communicable risk factors in Cambodia. Steps surveyCountry Report, Ministry of Health Cambodia, Asia.

41. Jayakrishnan R, Geetha S, Binukumar B, Sreekumar, lekshmi K (2011) Self reported tobacco use, knowledge on tobacco legislation and tobacco hazards among adolescents in rural kerala state. Indian J of Dent Res 22(2): 195-199.

42. World Health Organization (2010) Global adult tobacco survey (GATS) India Report 2009-2010.

\section{Your next submission with Juniper Publishers} will reach you the below assets

- Quality Editorial service

- Swift Peer Review

- Reprints availability

- E-prints Service

- Manuscript Podcast for convenient understanding

- Global attainment for your research

- Manuscript accessibility in different formats

( Pdf, E-pub, Full Text, Audio)

- Unceasing customer service

Track the below URL for one-step submission https://juniperpublishers.com/online-submission.php 